\title{
A CONTRIBUIÇÃO MARXISTA PARA O ESTUDO DAS RELAÇÕES INTERNACIONAIS
}

\author{
Tullo Vigevani \\ Aline Regina Alves Martins \\ Manoela Miklos \\ Priscila Rodrigues
}

Este artigo parte da constatação conhecida de que Marx não teria elaborado em seus trabalhos um conceito acabado de nação. Além disso, há grande controvérsia a respeito da existência de uma teoria marxista de Estado. Corolário imediato, Marx não teria produzido uma análise de relações internacionais consistente. Isso poderia levar à seguinte conclusão: haja vista a importância fundamental dos conceitos de nação e de Estado nas teorias dominantes da disciplina de relações internacionais, não haveria em Marx um instrumental teórico adequado para a compreensão, tal como as entendem essas teorias, das relações internacionais. Não obstante, nosso objetivo é mostrar que a teoria marxista contribui sim para a compreensão destas, inclusive as do século XXI.

A realização de nosso objetivo exige uma visão abrangente e não dogmática do que sejam as relações internacionais, inserindo-as plenamente nas relações sociais gerais. Atualmente, na busca da capacidade de explicar aquelas relações, as diferentes versões do marxismo não vulgar partem de fundamentos distintos dos que são utilizados pelo 
realismo, pelo liberalismo e por outras perspectivas teóricas. O estudo clássico das relações internacionais parte do pressuposto da existência de relações formais entre Estados soberanos o que implica na aceitação plena da ideia de nação e Estado. Inversamente, o emprego do método marxista no estudo das relações internacionais teria como resultado um instrumento de análise que passa pela desconstrução do conceito de Estado tal qual entendido pelas teorias dominantes de relações internacionais, isto é, pela desconstrução de um conceito considerado fundamental por tais concepções teóricas. Não desconhecemos que no final do século XX, e agora no XXI, há outras teorias no campo das relações internacionais - o construtivismo, por exemplo -, que reduzem significativamente o papel do Estado, mas essas teorias não têm como pressuposto o papel estruturador das relações de produção e o papel fundamental das classes sociais, pontos centrais para o marxismo e, ainda 112 que de forma atenuada, para este na sua versão gramsciana.

Buscaremos evidenciar que as análises marxistas de relações internacionais têm caráter normativo forte. Certamente não reconhecem na nação e no Estado a fonte principal do poder - de modo diverso, portanto, do estudo das relações internacionais como é tradicionalmente entendido, para o qual são o ponto de partida -, ou melhor, entendem que as relações entre os Estados devem buscar a explicação do que dá origem a elas, e essa razão não se encontra na própria formação estatal. Para as análises marxistas, a explicação das relações interestatais deve ser procurada nos movimentos profundos da história.

Quase toda a literatura que apresenta ou discute a disciplina de relações internacionais dedica algum espaço às contribuições marxistas. O mesmo pode ser identificado nas grades da maioria dos cursos dessa disciplina no Brasil e no mundo, bem como em obras de referência acerca de sua teoria (Russett e Starr, 1992; Baylis, Smith e Owens, 2008). 
Há reiteradas referências às contribuições de cunho marxista ou àquelas que lhe são tributárias, total ou parcialmente, como a teoria da dependência (Cardoso e Falletto, 1973; Marini, 2000) e, a partir dos anos 1970, à obra de Antonio Gramsci. No Brasil, os manuais de relações internacionais (Nogueira e Messari, 2005; Sarfati, 2005) em geral dedicam um capítulo específico ao marxismo; em alguns casos, à teoria da dependência, ao sistema mundo e, quase sempre, à teoria crítica. Tais referências corroboram a ideia que nos orienta: o marxismo é uma teoria social que tem desdobramentos importantes para a disciplina de relações internacionais e, em sua esteira, muitas teses nele inspiradas foram desenvolvidas e suas contribuições para o desenvolvimento da disciplina são indiscutíveis. Desta ideia surge a nossa questão central: qual a contribuição marxista para a análise das relações internacionais?

Para responder a tal questão, seguiremos a seguinte estrutura: a) voltamos a Marx e às formas como as questões nacional e internacional são tratadas em sua obra, incluindo as ideias principais que explicaram o mundo, segundo os marxistas, nas primeiras décadas do século XX; b) a seguir, situaremos as análises marxistas contemporâneas, mostrando sua relevância para o desvendamento da economia política internacional e sua relação com o tema da hegemonia; c) por fim, apresentaremos a contribuição marxista para o estudo das relações internacionais a partir do desmembramento de dois temas: I) a incorporação da dimensão histórica no estudo dos fenômenos; II) o imperativo da necessidade de considerar a economia política como variável fundamental para o entendimento das relações internacionais.

\section{MARX, O NACIONAL E O INTERNACIONAL}

Examinaremos, nesta seção, a afirmação de que não há em Marx um conceito acabado de nação. O nosso propósito não é apontar uma lacuna na argumentação marxista, mas 
constatar os motivos pelos quais o autor deu a essa questão uma atenção distinta daquela dada a da formação do Estado nacional pelas correntes teóricas hegemônicas no campo das relações internacionais.

Para a tradição socialista, com o desenvolvimento do modo de produção capitalista, a ideia de nação aparece associada a um valor permanente e imutável capaz de transcender todas as divisões sociais da moderna nação burguesa. Marx buscou compreender qual o sentido ideológico da formação de um sentimento de nação no período da afirmação e consolidação do Estado moderno.

Para os socialistas, o Estado nacional não está livre das contradições do modo de produção capitalista, pelo contrário, ele é analisado como a expressão, por excelência, das desigualdades. Isso constitui o fundamento, para os marxistas, de todos os Estados modernos. Com o advento do capitalismo, ocorre a redefinição do poder político 114 e a emergência de uma forma institucional que distingue o poder público, domínio do Estado, do poder privado, competência exclusiva das forças de mercado. Marx rejeita essa separação à medida que ela tem a função de encobrir a verdadeira interdependência estrutural entre as esferas pública e privada. Essa disjunção confere as bases de sustentação e reprodução da sociedade capitalista. Aceitar a ideia de um Estado soberano o qual estaria acima dos interesses das classes que compõem a sociedade implica em aceitar as relações de alienação que estão na base do sistema capitalista. Identificamos assim o que Marx pensou a respeito do Estado: ele resulta dos interesses das classes dominantes, particularmente os da nobreza e da burguesia, para impor sua dominação. Por isso Rosenberg (1994, p. 172) afirma:

Qualquer teoria das relações internacionais, portanto, precisa começar por captar a singularidade histórica da 
soberania e da anarquia como formas sociais provenientes da configuração distinta das relações sociais que Marx chamou de modo de produção capitalista e reprodução da vida social.

Para Marx, ao assumir a representação da nação, a burguesia legitima a sua dominação mediante o controle político e ideológico do Estado (Marx e Engels, 1967). Isso explica, como faz Mármora (1986, p. 10), as razões pelas quais em Marx não há preocupação específica pelas relações entre Estados: “[...] tratando de negar e desmistificar assim a suposta 'soberania' do Príncipe, Marx inverteu as relações, convertendo [...] Estado e nação em variáveis dependentes ou simples reflexos da sociedade civil."

Na discussão teórica ou no debate político, um conceito crítico reiterado pelos marxistas é que, ao proclamar a igualdade formal de todas as nações, omitem-se as verdadeiras relações de dependência e dominação, determinadas por fatores econômicos e sociais. A teoria crítica de matriz marxista não afirma que as concepções teóricas tradicionais da disciplina das relações internacionais - realistas e liberais em primeiro lugar-, não levam em conta as diferenças e as assimetrias de poder, mas sim que estas não consideram essas assimetrias em suas causas. "Ordens mundiais - para retornar à afirmação de Gramsci citada anteriormente neste ensaio - são fundamentadas em relações sociais" (Cox e Sinclair, 2001, p. 140). Ao considerar a obra de Marx, pode-se deduzir que as teorias do mainstream da disciplina de relações internacionais não consideram adequadamente as razões que determinariam o sistema internacional e suas mudanças. $\mathrm{O}$ foco da análise dessa disciplina, mesmo em suas versões contemporâneas - como o globalismo, de matriz liberal -, tem no Estado o seu ponto de partida fundamental. Em alguns casos, os globalistas mais radicais buscam reduzir o papel do Estado com o objetivo 
de maximizar a centralidade do capitalismo e do mercado, colocados como eixos centrais e reguladores das relações sociais (Rosecrance, 1986; Ohmae, 1996). É importante ressaltar que, por certo, os globalistas não consideram as contradições estruturais do modo de produção capitalista. Consideram seus problemas, inclusive suas inconsistências e crises; mas tudo isso não seria estrutural, seriam limitações atribuíveis a erros, falta de capacidade analítica, anacronismos, irregularidades de mecanismos geralmente adequados. Em oposição a essa perspectiva, a análise de tipo estrutural, inerente ao marxismo, explica as relações internacionais ao buscar entendê-las de forma a ressaltar suas características fundamentais, determinadas pelas relações sociais, pelas formas de produção e pelo desenvolvimento da técnica. Isto é, em última instância determinadas pelos interesses de classe.

Rosenberg (1994, p. 55) sugere que o sistema interna116 cional e suas mudanças só podem ser compreendidos se percebermos de outro modo o sistema de Estados. "Nós temos de encontrar maneiras de ver a forma do nosso sistema de Estados como a expressão geopolítica de uma totalidade social mais ampla”. É importante considerar que esse debate, tanto no campo acadêmico quanto no campo político, ajudaria à formulação de interpretações considerando os movimentos profundos da história, sobretudo contribuiria à análise crítica dos acontecimentos internacionais, viabilizando melhor compreensão das mudanças em curso. Significaria a introdução com mais força nas análises de relações internacionais, dos temas econômicos e históricos numa perspectiva crítica.

Marx não elaborou um estudo sistemático e acabado sobre a ideia de nação. Contudo, não ignorou completamente o tema. Ainda que a questão não seja objeto central das reflexões de Marx, estas oferecem contribuição importante para o estudo das relações internacionais - ainda que 
o faça a partir de um prisma distinto daquele adotado pelas teorias hegemônicas da disciplina.

Segundo o modelo de revolução defendido por Marx e Engels, as forças produtivas se desenvolveriam de forma a incluir todo o mundo civilizado, tendo como centro a Europa Ocidental e Central, e se unificariam as múltiplas lutas de classes existentes tanto nos países avançados quanto nos países atrasados. No horizonte, superadas as desigualdades, os socialistas não estariam dispostos a conceder legitimidade a instituições de cunho nacional.

Além disso, a falta de uma teoria do Estado-nação - ou seja, sua redução a uma teoria da sociedade burguesa - traz como consequência a falta de uma teoria marxista de relações políticas internacionais: o internacionalismo marxista não contém qualquer definição positiva das relações entre as nações durante a transição para o socialismo. Mas, de fato, contém uma negação teórica destas relações e de sua necessidade (Mármora, 1986, p. 11).

Consequentemente não é central o tema das relações entre Estados; não ganha relevância a elaboração a respeito das formas de estruturação do sistema internacional. Em síntese, "a constituição, funcionamento e transformação das relações internacionais são fundamentalmente regidos por relações sociais de propriedade" (Teschke, 2003, p. 273). Ainda que o marxismo não tenha uma reflexão específica sobre relações internacionais da maneira como são analisadas pelas teorias dominantes da disciplina, ao tomá-las como relações entre Estados, ele opera para a desconstrução dos princípios que orientam tais teorias e que sustentam a própria sociedade capitalista. Os marxistas, considerando suas diferentes correntes, entendem que a crítica de tal sociedade é instrumento fundamental e deve ser incor- 
porada ao debate da teoria das relações internacionais. Isso vale tanto no caso em que privilegiemos as relações entre Estados quanto no caso em que consideremos as relações internacionais como aquelas entre instituições e demais atores que operam ao largo do Estado. Nessa perspectiva, o marxismo ajudaria para a compreensão do mundo atual e as razões da hegemonia e de sua crise. Aproximamo-nos, assim, da ideia de que a teoria marxista pode contribuir para a compreensão dos ciclos econômicos e políticos, portanto, para o esclarecimento das razões históricas que explicam a hegemonia, sua predominância e seu declínio, no sistema internacional.

O emprego do método marxista tem como pressuposto a desconstrução do conceito de Estado tal qual aceito pelas correntes teóricas que compõem o mainstream da disciplina de relações internacionais. Por isso a crítica ao realismo, mas também - sobretudo nos anos 1990 e no século XXI -, 118 ao liberalismo.

Fica agora claro o nosso objetivo: precisar e aproximar-nos cautelosamente à resposta da pergunta central: qual a contribuição do marxismo para o estudo das relações internacionais? Rosenberg (1994, pp. 55-56) responde de modo categórico. Ao perceber o sistema de Estados como expressão de uma totalidade social, conclui que qualquer relação política entre eles resulta, por sua vez, de relações sociais de produção.

[...] se o caráter das relações políticas e a forma do Estado variam de um tipo de sociedade para outro de maneira que correspondam à forma mutante das relações de produção, então não se aplicaria algo similar ao caráter das relações geopolíticas e à forma do sistema de Estados?

Enfim, para o autor, essa forma de analisar as relações internacionais expõe as raízes e os segredos mais profundos 
destas da mesma forma que, para Marx, o desvendamento dos segredos do capital e de sua acumulação permite a crítica definitiva do sistema capitalista. Pode-se afirmar que essa ideia tem semelhança com o conceito de "forças profundas" utilizado por Renouvin (1966), especialmente com a ideia de sistema-mundo, originada em Braudel (1984) e desdobrada por Wallerstein (1979) e outros. Para Rosenberg (1994), a questão central é a estrutura de dominação social. Sua compreensão é o que permite entender as relações internacionais. Assim nos aproximamos do nosso alvo. Não é possível dizer tout court se há ou não uma teoria de relações internacionais marxista. É possível, sim, afirmar que o marxismo começa por inverter os termos de análise. Ao invés de explicar as relações internacionais partindo das relações entre os Estados, o que reconhecemos é uma narrativa convincente que desvenda as razões das estruturas sociais dominantes, fazendo derivar disso as relações de poder entre os Estados.

\section{FALTA DE DIÁLOGO E PERSPECTIVAS DE APROXIMAÇÃO}

$\mathrm{O}$ marxismo possui desenvolvimento independente em relação à disciplina acadêmica de relações internacionais e somente a partir dos anos 1980 inseriu-se como corrente de pensamento de reconhecido valor para tal disciplina. Fundamental para que ele atingisse esse status acadêmico foi o artigo de Cox e Sinclair (2001) publicado em 1981, "Social forces, states, and world orders: beyond international relations theory". A elaboração desse autor e de outros se desenvolvia há mais tempo, como mostra o artigo "The idea of international labor regulation", publicado em 1953, mas não tinha alcançado reconhecimento institucional. Apenas a partir dos anos 1980, os autores marxistas que pensavam as relações internacionais tomaram parte dos grandes debates - na crítica ao realismo e, mais recentemente, no fustigamento do liberalismo. 
No final do século XIX, deram-se as primeiras tentativas de aplicar o marxismo à compreensão das relações internacionais. Autores como Bernstein (1978), Kautsky (1978) e Bauer (1987) contribuíram à discussão sobre as relações entre os Estados europeus, com incursões sobre a questão nacional e colonial. A obra com mais notoriedade nas décadas sucessivas, pelo grande peso político-institucional do autor, é a de Lênin (1987), em que o conceito de imperialismo é apresentado como estágio final do capitalismo. Nas primeiras décadas do século XX, autores marxistas como Luxemburgo (1985), Bukarin (1988) e outros aprofundaram as análises sobre economia política internacional. Esse debate foi precedido e acompanhado por estudos de importantes economistas (Hilferding, 1985; Hobson, 1981). Como aponta Halliday (2007, p. 70), a "tentativa do marxismo no período de 1900-1920 de teorizar o sistema internacional em torno do conceito de 'imperialismo', entendido como 120 a rivalidade estratégica interestatal, é uma das mais ambiciosas e criativas jamais feita antes". Passado um século, são visíveis traços dessas ideias no pensamento contemporâneo: na análise do papel do capital financeiro, na própria ideia de globalização que lembra longinquamente a de super-imperialismo de Kautsky (1978) e de Hobson (1981).

Apesar do esforço de autores marxistas para a compreensão das relações internacionais, até os anos 1970 o marxismo não ocupou espaço confortável nos grandes debates da disciplina, permanecendo no campo da práxis política, muitas vezes sofrendo um processo de esclerosamento doutrinário. Na maioria das vezes, os manuais acadêmicos dessa disciplina, quando mencionam marxismo, referem-se aos debates do final do século XIX e das primeiras décadas do XX. Essa distância entre os estudos marxistas e os debates da disciplina de relações internacionais - separação muito maior do que nos outros campos das ciências humanas e sociais -, encontra explicação em muitos fatores, mas vale 
ressaltar a hegemonia das escolas norte-americanas e britânicas, em que o marxismo não desempenhou papel relevante em toda a primeira metade do século XX e mesmo no período imediatamente sucessivo à Segunda Guerra. Some-se o fato que a teoria marxista foi por longo tempo, ao menos pelo senso comum, apontada como instrumental à fundamentação das políticas dos regimes comunistas, que com o stalinismo eram autoritários e fortemente burocráticos. Teschke e Lacher (2007, p. 566) pontuam que "O discurso ocidental das relações internacionais, portanto, constituiu-se ao exorcizar a questão do capitalismo do debate sobre as origens da grande guerra e das condições para a paz duradoura”.

Os anos 1970 apresentaram desafios ao paradigma realista, até então visão dominante na disciplina de relações internacionais. À época, mudanças significativas no plano das relações internacionais resultaram em transformações também importantes nos rumos da disciplina. Um conjunto de circunstâncias históricas definiu um novo cenário internacional e conferiu às novas abordagens liberais legitimidade inédita. Isto é, questões que já faziam há muito parte do debate político, pediam teorias explicativas no campo teórico. Esse contexto expôs as limitações da teoria realista para compreender a transformação e favoreceu a ascensão de novos temas, inicialmente numa perspectiva liberal.

Na sequência, os debates sobre os novos atores e sobre as razões das mudanças possibilitaram a algumas interpretações marxistas ocupar maior espaço na disciplina de relações internacionais. Possivelmente, os críticos do realismo e do neorrealismo acreditaram encontrar nos marxistas e na teoria crítica um suporte para a demolição de uma construção efetivamente sólida. Nos anos 1970 e 1980, como é amplamente conhecido, os marxistas, particularmente os gramscianos, engajaram-se nas polêmicas intelectuais criticando pesadamente o realismo e o neorrealismo. Em 
crítica direta a Waltz (1979), Cox (1986, p. 211) esquadrinhou o realismo mostrando sua funcionalidade explicativa das relações efetivamente existentes, portanto do status quo que resultaria da Guerra Fria, ao mesmo tempo em que demonstrou sua incapacidade de compreensão das mudanças que, para ele (Cox), resultam exatamente das alterações nas relações de classe:

Desde a Segunda Guerra Mundial, alguns acadêmicos americanos, notadamente Hans Morgenthau e Kenneth Waltz, transformaram o realismo em uma teoria para a solução de problemas. Embora fossem indivíduos com conhecimento histórico considerável, eles tenderam a adotar a visão fixa e a-histórica característica das teorias para a solução de problemas ao invés de se afastarem dessa concepção, à maneira de E. H. Carr, e tratá-la como historicamente condicionada e, portanto, 122 suscetível à mudança.

Nos anos 1990 e 2000, a crítica voltou-se, sobretudo, aos liberais e neoliberais que, segundo os marxistas, não compreenderam o significado das novas forças que irrompem no mundo todo e não podem compreender o fracasso do liberalismo econômico. Gowan (2006, p. 128) é explícito:

Embora os estudantes de relações internacionais sejam convidados a entrar em um 'grande debate' entre 'realismo' e 'liberalismo', na política externa norte-americana real os realistas tendem a tornar-se mais críticos, enquanto o chamado campo liberal tem sido largamente capturado pelo imperialismo agressivo.

Enfim, na perspectiva aberta pelas grandes questões do século XXI, um marxismo renovado, afastado de suas versões vulgares, que busca analisar criativamente os novos proble- 
mas colocados pelas relações internacionais, contribui para debates que cobrem um amplo espectro de temas.

\section{CONTRIBUIÇÃO MARXISTA PARA A INTERPRETAÇÃO DAS RELAÇÕES INTERNACIONAIS}

Como argumentamos, não há em Marx reflexão específica a respeito de relações internacionais. Mármora (1986, p. 175) sugere que isso é consequência da forma como o autor considera a nação: "O conceito de nação, por conseguinte, parece estar inseparavelmente unido ao conceito de hegemonia burguesa”. Se nação tem relação inseparável com burguesia, compreender a natureza e as relações entre as nações implica entender as raízes da hegemonia burguesa. Conforme Rosenberg (2007), Marx nunca produziu o que poderia ser considerada uma teoria de um sistema de Estados soberanos. O resultado dessa constatação é a ausência de diálogo entre o debate marxista e o desenvolvimento da disciplina de relações internacionais, particularmente quando considerada como originária do campo da ciência política ou do direito. Mais do que isso, segundo Rosenberg (2007), Marx decifrou a substância da própria soberania, mostrando que ela é funcional ao conceito de autonomia do Estado frente à sociedade. Em função disso, mostraremos que o marxismo oferece elementos para a compreensão das relações interestatais com base na evolução das relações sociais e econômicas e a partir do entendimento das estruturas sociais e de dominação. Dessa maneira consegue-se apreender as razões profundas que determinam os problemas de segurança internacional e o ascenso e o declínio da hegemonia de um determinado Estado.

Os autores que se inspiram no marxismo trabalham conceitualmente sob diferentes perspectivas. Como vimos, há marxismos diferentes. Alguns utilizam de forma direta o método elaborado por Marx em suas principais obras, em 
particular n' O capital e nos Grundrisse. Rosenberg (1994) sustenta que a ideia de relações internacionais pode ser compreendida como um fetiche, conceito desenvolvido por Marx para explicar o significado da mercadoria na modernidade. Nessa perspectiva metodológica, Rosenberg traça uma analogia entre o conceito de anarquia, utilizado por Marx para explicar o funcionamento do modo de produção capitalista, e o conceito de anarquia utilizado em relações internacionais. Esse paralelo é feito para demonstrar que a ideia de anarquia encobre as verdadeiras relações materiais entres as partes. Num caso, encobre as relações entre trabalhadores e capitalistas, no nosso caso, encobre as relações entre Estados.

[...] o que distingue a forma moderna do poder geopolítico não é o fato deste ser exercido por uma pluralidade de unidades independentes (anarquia em geral), mas o fato de 124 já não incorporar relações interpessoais de dominação (o que elimina a independência formal dos dominados), sendo impessoal, mediado por coisas (Rosenberg, 1994, p. 146).

Outros autores, ainda que próximos de Marx, utilizam conceitos elaborados no século XX, particularmente os de Gramsci - talvez o mais conhecido dentre eles seja Robert Cox. Desenvolveu-se nessa esteira a escola que ganhou o nome de teoria crítica. Tendo em vista as intersecções explícitas entre teoria crítica e marxismo, ainda que uma não se superponha à outra, teremos em conta que os autores do campo de relações internacionais que se reconhecem na teoria crítica, em diversos aspectos contribuem de forma convergente com as correntes marxistas. Cox, inserido nesse debate, transpõe o conceito de hegemonia de Gramsci para as relações internacionais. Cox utiliza esse conceito de forma inovadora, para um objetivo que certamente não foi trabalhado em profundidade pelo próprio Gramsci. Este 
abordou relações internacionais apenas marginalmente. Com isso, Cox constitui-se em referência para o conjunto da teoria crítica. Em 1983, afirmava:

Não surpreendentemente, Gramsci não tinha muito a dizer diretamente sobre relações internacionais. No entanto, descobri que o pensamento de Gramsci era útil para compreender o significado de organização internacional, com o qual eu estava preocupado na época. Seu conceito de hegemonia foi particularmente útil, mas também foram valiosos vários conceitos que ele tinha criado ou desenvolvido a partir de outros (Cox e Sinclair, 2001, p. 124).

Dessa forma, o conceito de hegemonia surge como explicativo não só do conflito entre Estados e das relações de dominação, mas também dos outros aspectos que determinam as relações de poder: as relações econômicas, culturais, ideológicas. Essas relações estabelecem-se sobre bases profundas, sobre as estruturas que permeiam a organização social e o desenvolvimento do processo histórico. A hegemonia global começa com a expansão de uma hegemonia estabelecida no âmbito nacional. Para Cox e Sinclair (2001, p. 137), o conceito torna-se chave para explicar as relações internacionais:

Hegemonia mundial pode ser descrita como uma estrutura social, uma estrutura econômica e uma estrutura política; e não pode ser simplesmente uma dessas coisas, mas deve ser todas as três. Hegemonia mundial, além disso, é expressa em normas universais, instituições e mecanismos que estabelecem regras gerais de comportamento para os Estados e para as forças da sociedade civil que atuam por meio das fronteiras nacionais - regras que suportam o modo de produção dominante. 
Relevante é mostrar que essa concepção de relações internacionais é crítica na medida em que se considera, como lembra Adler (1999, p. 221), “externa em relação à ordem prevalecente do mundo e se pergunta como essa ordem surgiu. Mas também é de resolução de problemas, no sentido de que, uma vez reificadas, as instituições e as práticas toma o mundo como o encontra como o cenário dado para a ação". Portanto, mais uma vez verificamos que, para as concepções marxistas e da teoria crítica, o conceito de hegemonia não produz um corte entre a hegemonia interna e a internacional; uma representa a continuidade da outra e as duas se retroalimentam.

Autores influenciados pela teoria crítica vêm contribuindo para o debate das relações internacionais, com inserção significativa no mundo acadêmico. Os trabalhos de Craig Murphy (2005), que se inserem nesse debate pelo viés da análise das instituições internacionais, demonstram 126 a contribuição marxista e, mais especificamente, gramsciana para a compreensão de temas específicos das relações entre Estados. Suas obras desvendam o papel de correia de transmissão que instituições e organizações internacionais desempenham ao generalizarem e tornarem hegemônicos, sob o manto de valor universal, conceitos formulados nos países centrais e funcionais aos interesses de seus grupos dirigentes. A intenção do autor é explicitamente a de interpretar as instituições internacionais à luz dos conceitos de Marx e Gramsci, procurando apontar como tais instituições estabelecem um consenso de cunho universal respaldado no interesse do Estado hegemônico.

A influência dessas ideias é visível no mainstream da disciplina de relações internacionais, ainda que as inter-relações não tenham sido suficientemente estudadas. Tanto no campo do realismo quanto no campo liberal - sem partir dos mesmos pressupostos teóricos e muitas vezes tendo objetivos totalmente distintos -, ganham peso alguns 
dos argumentos da teoria crítica e do marxismo. Quando Nye Jr. (2002), por exemplo, discute o conceito de soft power, significa que a ideia de hegemonia, como utilizada por Cox para a compreensão das relações internacionais, transcende o debate da teoria crítica. As teorias marxista e crítica desconstroem o caráter da hegemonia, mostrando sua funcionalidade para a dominação. Trata-se de compreender a funcionalidade da hegemonia, para que serve, partindo disso para, normativamente, criar os elementos de sua desconstrução. A crítica da hegemonia tem contribuído para analisar o significado dos valores chamados ou considerados universais, permitindo compreender seu significado, sua gênese, sua práxis e, eventualmente, sua metamorfose.

Reforçando nosso argumento relativo ao peso da teoria crítica para o debate da disciplina de relações internacionais, lembremos como os construtivistas em alguns aspectos têm intersecção com ela. Ao discutirem o significado e o peso das ideias, mostram como elas têm grande relevância na determinação da agenda internacional e na discussão das normas que prevalecem. Ao destacarem o peso dos grupos epistêmicos, mesmo sem considerarem qualquer análise de classe, reforçam a percepção de que a articulação dos interesses é um elemento básico na determinação da agenda (Adler, 1999; Wendt, 1999). Essa forma de conceber as relações internacionais pode ser retrabalhada de forma a evidenciar o significado que têm os interesses dos dominantes e dos dominados.

Com isso nos aproximamos do objetivo desse texto: discutir qual a contribuição marxista para o estudo das relações internacionais. Pretende-se mostrar que a análise das relações entre os Estados não pode prescindir da compreensão das relações entre as classes nos planos nacional e internacional, da materialidade dessas relações e das ideias por elas produzidas. 


\section{INSTRUMENTOS MARXISTAS PARA A ANÁLISE DE RELAÇÕES INTERNACIONAIS}

Inicialmente afirmamos que não há em Marx uma teoria específica para as relações entre Estados nos moldes das teorias dominantes da disciplina de relações internacionais. Em seguida, apresentamos o diálogo limitado, mas crescente, entre tal disciplina e o marxismo. Nas palavras de Cox (1986, p. 248), falando nos anos 1980 do debate norte-americano: "Se há qualquer diálogo entre a ciência norte-americana das relações internacionais e o marxismo, é um diálogo de surdos”. No momento seguinte, situamos as análises marxistas contemporâneas para a compreensão das relações internacionais e pontuamos que os autores inseridos nesse contexto teórico têm produções muito distintas. Esta seção do texto parte do argumento de que é possível diagnosticar, ao analisar essa produção diversificada, um mínimo denominador comum. Como antecipamos 128 no começo deste artigo, identificamos duas preocupações de inspiração marxista presentes nos autores apresentados e em outros: de um lado, a incorporação da dimensão histórica no estudo dos fenômenos e a percepção da impossibilidade de uma ciência neutra, de outro, o imperativo da necessidade de considerar a economia política como variável fundamental para o entendimento das relações internacionais. A consideração destes elementos representa necessariamente o questionamento do alcance explicativo das teorias dominantes da disciplina de relações internacionais, particularmente as racionalistas, e nos leva a concluir que o marxismo tem contribuição ao debate a respeito do sistema internacional.

\section{Incorporação da dimensão histórica}

Em relação à importância da produção de uma teoria que não negligencie a dimensão histórica, em A ideologia alemã (Marx e Engels, 1999) afirmam que a vida social é compreen- 
dida a partir da ideia da atividade prática, ou seja, é produto da ação humana. A realidade deve ser apreendida como práxis, não há como se abstrair o curso da história das relações sociais. A realidade, produto social, é construída pelo próprio homem e este é um ser histórico, não havendo como desvinculá-lo do contexto no qual está inserido. A valorização da sociologia histórica, com consequências para as relações internacionais, parece convergir com a perspectiva teórica dos autores marxistas e da teoria crítica. Theda Skocpol (1984, pp. 1-2) afirma: "Estudos verdadeiramente históricos e sociológicos [...] questionam as estruturas sociais ou processos entendidos como situados concretamente no tempo e no espaço".

O marxismo clássico sugere que, para compreender como se processam as relações entre as unidades políticas num determinado período histórico, é necessário olhar primeiramente para o estado de evolução das forças produtivas, a saber, para o prevalecente modo de produção, bem como para as relações sociais de produção. Como é por intermédio do conhecimento destas últimas que se adquirem subsídios para o entendimento da natureza e do próprio ser humano, faz-se necessário o estudo das forças produtivas para o entendimento das relações e do sistema internacional.

Apreender os fenômenos em sua complexidade exige partir do estudo do simples e de suas peculiaridades (Marx, 1978). As forças produtivas são o motor da história e o desenvolvimento destas é o fator dinâmico sobre o qual repousam as relações sociais. Os que utilizaram o método marxista no final do século XX e agora nos anos 2000, dentre eles os que se preocuparam especificamente com as relações internacionais, avançaram na compreensão da relação entre forças produtivas e os outros fatores que influem na determinação da dominação, particularmente os fatores políticos. Contudo, deve-se ressaltar que o marxismo não 
detém plena capacidade explicativa em relação a fenômenos de grande importância. Há questões que não encontram explicações econômicas ou políticas apenas. Elementos culturais (Weber, 1985), psicológicos, questões de identidade, dignidade, como sabemos, têm grande significado. Temas esses discutidos por culturalistas e construtivistas, mas ainda insuficientemente absorvidos pelas teorias. Cabe sublinhar que essas perspectivas também trabalham contra os conceitos racionalistas, de rational choice etc.

Para Marx, é necessário olhar para a dinâmica das relações sociais de produção para o entendimento da realidade. Ampliando esse raciocínio, Rosenberg (1994) sustenta que as relações internacionais compõem um quadro maior de relações sociais e, portanto, sua análise exige a exata compreensão do estágio de desenvolvimento das forças produtivas. A esse respeito, Gramsci (1971, p. 176) afirmava: "As relações internacionais precedem ou sucedem (logicamen-

130 te) relações sociais fundamentais? Não pode haver dúvida que elas sucedem”. A adoção da perspectiva utilizada pelos marxistas e pelos gramscianos coloca críticas fortes e limites ao potencial analítico das correntes que predominaram na análise das relações internacionais durante todo o século XX. Sua adoção implica a negação da postura positivista adotada pelas escolas realista e liberal, que resulta na reificação e universalização dos objetos de estudo e é considerada pelos marxistas a-histórica. O resultado da crítica e consequente negação dessa postura positivista leva a uma interpretação mais refinada do sistema internacional, de suas crises e contribui para a explicação da emergência e decadência de hegemonias. Essa interpretação não tem a pretensão da neutralidade. É abertamente vista por seus formuladores como instrumento de desconstrução das hegemonias existentes. Sem dúvida, contribui para a explicação das mudanças sistêmicas, questão objeto de grandes polêmicas nas quais se evidenciaram as falhas explicativas particu- 
larmente do realismo, a não ser nos casos em que o processo histórico é claramente absorvido. Por isso, como vimos, o respeito de marxistas para autores como Carr (1981).

A crítica ao positivismo por parte dos autores marxistas tem a ver com um tema comum a eles, qual seja, a negação da possibilidade de neutralidade e de imparcialidade. Cox (1986) e Cox e Sinclair (2001) criticam Waltz e, por meio dele, os realistas particularmente num aspecto: a obsessão pela busca de regularidades e leis gerais. A consequência seria a incapacidade para explicar fenômenos que vão além das transformações tecnológicas e das modificações nas posições relativas dos atores. Essas mudanças são evidentes. O que os marxistas criticam é a limitação analítica em entender as interações produzidas pelas relações de dominação interna e externa aos Estados. Portanto, a questão não é o balanço de poder, mas as razões que o determinam. A estrutura não reside na tendência ao equilíbrio, mas nas formas de dominação.

Waltz (2000, p. 30) adapta sua interpretação sem romper com ela. A teoria permite que se assevere que um novo equilíbrio de poder se formará, mas não permite que se afirme quanto tempo ele durará”. Portanto, a teoria teria uma capacidade explicativa prévia, embora limitada. O autor reconhece alguns limites para a teoria, mas reafirma a certeza no tocante à permanência da regra da balança de poder. Os marxistas, por sua vez, entendem que a definição de "leis" limita ou até impede a capacidade de explicar as mudanças provocadas pela própria natureza dos atores e de suas formas de interação. Marx (1999, p. 14) afirma que "a vida social é essencialmente prática, todos os mistérios que levam a teoria para o misticismo encontram sua solução racional na práxis humana e na compreensão dessa prática”. Essa percepção se choca com a pretensa neutralidade científica. Por isso o positivismo e o racionalismo da disciplina de relações internacionais são criticados por Rosenberg 
(1994, p. 7): “o núcleo geopolítico do objeto da disciplina é ontologicamente distinto das estruturas mais amplas da reprodução social".

Para Rosenberg (1994), a compreensão da perspectiva histórica e da ideologia que lhe corresponde é fundamental. As relações internacionais, na essência, seriam um tipo de relações entre pessoas, grupos, estamentos, classes. Trata-se de compreender o que os marxistas consideram as razões profundas que modelam as próprias relações internacionais. Quanto ao método, os marxistas, tal qual define Cox (1986, pp. 243-244), rejeitam a ideia de fundamentar leis de bronze da história e buscam a compreensão dinâmica do objeto.

A abordagem historicista para a ciência social não prevê qualquer lei geral ou universalmente válida que possa ser explicada a partir do desenvolvimento de teorias de aplicação generalista. Para o historicismo, tanto a natureza humana quanto as estruturas de interação humana mudam, mesmo que muito lentamente. A história consiste nesses processos de mudança. Não se pode falar, portanto, de "leis" de validade generalista que transcendam eras históricas, nem de estruturas exógenas ou anteriores à história.

Há um núcleo central na crítica às teorias de relações internacionais essencialmente racionalistas que prevaleceram nas últimas décadas, especialmente a partir do fim da Segunda Guerra: "Toda teoria é sempre para alguém e para algum fim" (Cox, 1986, p. 207). Essa chave interpretativa surge na lembrança da impossibilidade de interpretações neutras e na crítica às regularidades e leis gerais. Reforçando esse argumento, Teschke (2003, p. 274) afirma que:

As relações internacionais são uma ciência social. E como tal, não estão à parte da reprodução cotidiana das 
estruturas de dominação e exploração. Mas o paradigma dominante das RIs, o neo-realismo e seu irmão racionalista, o neoliberalismo, permanecem atados a uma concepção positivista da ciência para explicar a política internacional. A subsunção do comportamento internacional sob uma lei geral que alega objetividade é teoricamente empobrecedor intelectualmente debilitante.

Identificamos assim um fio condutor fundamental nas análises marxistas: a crítica das leis gerais e a instrumentalização da história para demonstrar o que foi previamente definido como ponto de partida. Nesse sentido, Rosenberg (1994) aponta para a historicidade na formulação dos conceitos. Compreendemos, portanto, a crítica ao mainstream. Vejamos agora a contribuição que consideramos particularmente relevante do marxismo e da teoria crítica à teoria das relações internacionais: a incorporação da economia política como variável imprescindível.

\section{Conexão entre as dimensões econômica e política}

Um tema central dos autores de inspiração marxista que estudam as relações internacionais é a superação da cisão entre economia e política. Para eles, sendo essenciais as questões da dominação e da hegemonia, não há como compreendê-las sem recorrer às suas expressões nacionais e internacionais. Rosenberg (1994), Teschke (2003) e Rupert (2007), inspirados em Marx, remontam às bases do nascimento do Estado moderno, construção que resultaria do desenvolvimento histórico da economia capitalista. No plano jurídico-formal, um contrato fundador regulou o processo de extração do produto da força de trabalho do proletariado, subordinado-o à autoridade do domínio privado. A teoria política clássica contribuiu para fundamentar essa ideia, inicialmente com a obra de Locke (1983), depois levada ao campo da economia por Smith (1999). Isto 
é, no capitalismo, o exercício da extração do excedente não é responsabilidade do poder público, do Estado, e sim de competência das forças de mercado. Ao menos foi dessa forma que a burguesia argumentou, tanto no contexto em que sustentou o domínio monárquico-absolutista, quando no momento em que decidiu dele se libertar (Anderson, 1985). As relações de troca e as novas formas de poder nelas embutidas ficam a cargo da economia, do "não político", enquanto se dá uma espécie de esvaziamento de certos poderes e atribuições do domínio político formal do Estado, agora denominado "Estado de direito". A esse respeito Rupert (2007, p. 136) afirma:

A reprodução das relações sociais capitalistas e o processo de exploração pressupõem, portanto, a separação formal entre política e economia, de forma tal que as duas esferas parecem estar relacionadas apenas externamente, e suas relações internas estão submersas e não podem ser percebidas.

A separação entre política e economia não é nova em diferentes versões do pensamento dos séculos XIX e XX. Para essas versões, as duas, política e economia, são importantes, mas deveriam seguir caminhos separados. Nos anos 1980 e 1990, a hegemonia liberal acentuou a crença de que a economia deixada às leis do mercado - uma leitura, diríamos, no mínimo simplista de Smith (1999) e Ricardo (2004) - produziria os resultados necessários ao enriquecimento global e a um razoável progresso harmonioso. A consequência desejada seria que a economia globalizada fortaleceria a interdependência, assegurando um horizonte de desenvolvimento para os países, inclusive aqueles da periferia. As relações internacionais sob a hegemonia liberal alcançariam um razoável equilíbrio, proporcionando aos países desenvolvidos mais importantes a continuidade 
do seu poder. Países em desenvolvimento, atraídos pelo interesse na estabilidade e pela possibilidade de usufruírem do crescimento geral, se somariam a eles. Gill (2004, p. 8) descreve esse processo no qual a perspectiva do mercado prevaleceria:

A ampliação do escopo do mercado nos anos 1980 e provavelmente durante os anos 1990, somada a certas mudanças na tecnologia e comunicação, contribui para o crescente poder estrutural do capital móvel internacional. Por outro lado, o Estado como uma entidade institucional e social também cria possibilidades para a limitação de tal poder, em parte devido aos bens políticos e serviços que ele fornece aos capitalistas e à autonomia institucional que possui.

O esforço de desregulamentação dos mercados e a diminuição do campo de atuação do Estado deram novo fôlego à separação do político do econômico. Velasco e Cruz (2007) assinala a relação entre política e economia. Ao discutir o papel do neoliberalismo nas formulações econômicas nacionais e na economia internacional, aponta a concepção contraditória dessa escola ao separar e introduzir ao mesmo tempo o fator político. A contradição se evidencia ao denunciar a doutrina que faz do intervencionismo estatal o seu leitmotiv e, concomitantemente, estimula a mobilização crescentemente intrusiva do Estado, necessária à implementação das políticas que ele informa. Nesse contexto, o marxismo e a teoria crítica dão uma contribuição significativa às análises das relações internacionais, já que incidem diretamente procurando desvendar os significados da desregulamentação e da alegada diminuição do papel do Estado.

Marx, ao diagnosticar o fenômeno da separação entre economia e política, rejeita essa distinção. Ela encobre, para o autor, a verdadeira interdependência estrutural entre as 
esferas pública e privada. A emergência de uma forma institucional que distingue a esfera do Estado da esfera da economia, nesse sentido, seria uma abstração necessária para a consolidação e para a perpetuação do sistema capitalista. "A emergência de esferas institucionais distintas, chamadas de Estado e de economia, é a marca da sociedade capitalista" (Rosenberg, 1994, p. 126).

No plano metodológico a cisão entre economia e política também se verifica e tem consequências. Rosenberg (1994, p. 3) explica:

Esta separação formal tem agora um século de idade e data do nascimento da economia pura, resultado da chamada revolução "marginalista" da década de 1870 . As relações internacionais Realistas estão entre as várias disciplinas acadêmicas fundadas a partir de tal separação, constituindo-se como o estudo das relações políticas entre Estados. Mais recentemente, este processo levou ao surgimento do novo campo da economia política internacional, que foca precisamente na interação causal entre a política internacional e a economia internacional. O surgimento deste novo campo é entendido como uma inovação que pressiona fortemente as fronteiras disciplinares entre as RIs e a economia. Bem, talvez ele o seja. E, certamente, a pergunta "qual é a relação entre os Estados e os mercados?" é interessante e importante.

Rosenberg (1994) ressalta que autores de referência reconhecida no campo das relações internacionais formularam objeções a essa separação. Carr (1981) é um deles, ao mostrar que separar política de economia dificulta, ao invés de facilitar o estudo. Susan Strange (1988) também buscou reintroduzir a relação casual entre economia internacional e política internacional. Não desconhecemos o fato de que tanto parte dos realistas (Gilpin, 1987) quanto parte dos 
liberais (Rosecrance, 1986) aceita e utiliza a relação entre economia e política. O que os marxistas (Gowan, 2009) constatam, contudo, não é apenas a existência da relação entre economia e política, é mais do que isso, eles identificam as relações sociais capitalistas que dão sustentáculo a essa separação. As falhas de liberais e de realistas estariam em não identificar as razões profundas das inter-relações entre economia e política. Nisso residiria o positivismo e a utilização da lógica de rational choice que para os marxistas inviabilizaria a compreensão das próprias relações internacionais. Lembramos que nessa crítica há espaços de overlap. Isto é, instrumentos de análise com fundamento técnico podem produzir resultados úteis quando as variáveis utilizadas são adequadas e quando não se quer, com esses meios, encobrir a totalidade do espectro analítico.

Como consequência, a distinção entre o político e o econômico resulta na perda de alcance analítico das teses elaboradas pelas escolas dominantes da disciplina de relações internacionais. Todos reconhecem a importância da questão econômica. No entanto, há modos distintos de considerá-la: a economia pode ser vista de forma positivista, como um dado do problema, como um input muito importante na análise das relações entre os Estados, um fator de poder. Kennedy (1988), como outros autores, ao discutir o significado do over extension como fator explicativo da decadência dos Estados, focaliza a atenção no papel da economia. A contribuição marxista, em oposição, está na introdução da questão econômica como fator explicativo não apenas das relações de poder, mas das formas como se desenvolvem as relações entre os Estados, buscando compreender sua estrutura e sua dinâmica.

Há uma relação de interação entre as esferas econômica e política e somente uma reflexão que não exclua a variável econômica para o estudo da política, e vice-versa, é capaz de compreender o sistema internacional em sua totalidade. 
Enfim, cabe sublinhar que autores pertencentes a uma mesma escola, inclusive marxista e da teoria crítica, podem divergir quanto às conclusões. Confirma-se a interpretação de que o marxismo é um instrumento de análise, sem a pretensão de buscar formas homogêneas de interpretação e, portanto, sem a intenção de estabelecer previsibilidade no tocante ao futuro. Menos ainda possui a pretensão de previsibilidades exatas, determinismos, como pretenderam epígonos e engessadores dessa forma de pensar. A alternância de interpretações confirma que o marxismo não vulgar é um instrumento de análise relevante para o estudo das relações internacionais sem pretensões de previsão determinista dos futuros cenários.

A adoção da perspectiva marxista implica na desconstrução dos princípios compartilhados pelas teorias dominantes da disciplina das relações internacionais. Para tanto, é preciso admitir que política e economia constituem-se 138 mutuamente e não podem ser consideradas isoladamente.

O estudo do sistema internacional utilizando o instrumental marxista e da teoria crítica é útil e importante para a compreensão dos fundamentos sobre os qual se apoia esse mesmo sistema, para a compreensão das relações entre os Estados, em especial para a compreensão da expansão da economia e dos pilares do capitalismo em escala mundial. Essa perspectiva, em especial a preocupação com a economia política, mostra-se eficiente para a análise do sistema capitalista mundial e da ordem política internacional.

A contribuição da análise marxista foi prejudicada durante décadas pela instrumentalização que dela fizeram os países do chamado socialismo burocrático, em primeiro lugar, a União Soviética. Se não pode ser negada a relação 
entre o instrumento teórico e o seu uso político, da mesma forma não pode ser desconsiderada a relação entre os valores liberais e o uso que deles foi feito. Nos dois casos, há fortes conotações negativas e positivas.

Acreditamos ter demonstrado que o marxismo contribui para proporcionar uma interpretação interessante das relações internacionais: 1) a conjugação dos níveis de análise, político e econômico e 2) a preocupação em incluir as dimensões histórica e sociológica. Isso possibilita respostas adequadas, com potencial normativo, para o mundo contemporâneo. Respondemos a questão a respeito da contribuição do marxismo à análise de relações internacionais retomando alguns princípios. Em particular, resgatamos a ideia marxista de que as relações internacionais, quando consideradas como relações unicamente entre Estados nacionais, refletem a hegemonia do pensamento capitalista. Não considerar a historicidade das formações sociais impede o desvendamento da natureza dos atributos conexos, soberania, anarquia, dominação, hegemonia, assimetria. Mostramos que, em Marx, não há uma discussão específica sobre relações internacionais. Ao mesmo tempo, discutimos como o marxismo oferece instrumentos para analisar, a partir das relações de classe e considerando inúmeros campos de conhecimento - história, economia, sociologia, direito, ciência política - as forças profundas que determinam a política mundial e que explicam as relações entre Estados.

Demonstramos a importância de reconectar economia e política e verificamos que no mundo intelectual há esforços nesse sentido. Esse vínculo sempre existiu, mas foi instrumentalizado, particularmente pelo pensamento liberal. Nesse processo, ora prevalece a política, ora a economia. Em ambos os casos, oculta-se o papel do Estado enquanto manifestação de interesses heterogêneos que projetam-se na ação internacional. Trata-se de saber quem ganha e 
quem perde na ordem internacional vigente. Essa questão, presente nos trabalhos de Strange (1988), Cox e Sinclair (2001) e outros, é estratégica e indica em boa medida a contribuição do marxismo, dos gramscianos e da teoria crítica. Buscar a resposta a essa questão é a contribuição possível.

\section{Tullo Vigevani}

é professor da Unesp e do Programa de Pós-Graduação em Relações Internacionais San Tiago Dantas (PPGRI) da Unesp, Unicamp e PUC-SP.

\section{Aline Regina Alves Martins}

é doutoranda em Ciência Política pela Unicamp.

\section{Manoela Miklos}

é doutoranda em Relações Internacionais pelo Programa de Pós-Graduação em Relações Internacionais San Tiago 140 Dantas (PPGRI) da Unesp, Unicamp e PUC-SP.

\section{Priscila Rodrigues}

é bacharel em Relações Internacionais pela Unesp.

\section{Referências bibliográficas}

ADLER, E. 1999. "O construtivismo no estudo das relações internacionais". Lua Nova, n. 47, pp. 201-246.

ANDERSON, P. 1985. Linhagens do Estado absolutista. São Paulo: Brasiliense. BAYLIS, J.; SMITH, S.; OWENS, P. (orgs.). 2008. The globalization of world politics. Oxford: Oxford University Press: Oxford.

BAUER, O. 1987. La question des nationalités et la social-démocratie. Paris: Arcantère Éditions (t. 1).

BERNSTEIN, E. 1978. "La socialdemocracia alemana y los disturbios turcos". In: et al. La segunda internacional y el problema nacional y colonial (primera parte). México: Siglo XXI.

BRAUDEL, F. 1984. O Mediterrâneo e o mundo mediterrânico na época de Felipe II. São Paulo: Martins Fontes.

BUKHARIN, Nicolai. 1988. A economia mundial e o imperialismo. São Paulo: Nova Cultural. 
CARDOSO, F. H.; FALLETTO, E. 1973. Dependência e desenvolvimento da América Latina: ensaio de interpretação sociológica. Rio de Janeiro: Zahar.

CARR, E. H. 1981. Vinte anos de crise: 1919-1939. Brasília: Ed. UnB.

COX, R. W. 1986. "Social forces, States and world order: beyond international relations theory" In: KEOHANE, R. (org.) Neorealism and its critics. Nova York: Columbia University Press.

; SINCLAIR, T. J. 2001. Approaches to world order. Cambridge:

Cambridge Univesity Press.

GILL, S. 2004. "Globalization, neo-liberalism and reform". In: SINCLAIR, T. J. (org.). Global governance: critical concepts in political science. Nova York: Routledge.

GILPIN, R. 1987. The political economy of international relations. Princeton: Princeton University Press.

GOWAN, P. 2006. "A radical realist”. New Left Review, n. 41, pp. 127-137. . 2009. "Crisis in the heartland". New Left Review, n. 55, pp. 5-29.

GRAMSCI, A. 1971. Selection from prison notebooks of Antonio Gramsci.

Londres: Lawrence \& Wishart.

HALLIDAY, F. 2007. Repensando as relações internacionais. Porto Alegre: Ed. UFRGS.

HILFERDING, R. 1985. O capital financeiro. São Paulo: Nova Cultural.

HOBSON, J. A. 1981. Estudio del imperialismo. Madri: Alianza.

KAUTSKY, K. 1978. "La nacionalidad moderna”. In: BERNSTEIN, E. et al. La segunda internacional y el problema nacional y colonial (primera parte). México: Siglo XXI.

KENNEDY, P. 1988. The rise and fall of the great powers. Nova York: Random House.

LÊNIN, V. 1987. O imperialismo: fase superior do capitalismo. São Paulo: Global.

LOCKE, J. 1983. Segundo tratado sobre o governo civil. São Paulo: Abril Cultural.

LUXEMBURGO, R. 1985. A acumulação do capital: contribuição ao estudo econômico do imperialismo. São Paulo: Nova Cultural.

MARINI, R. M. 2000. Dialética da dependência: uma ontologia da obra de Ruy Mauro Marini. Petrópolis: Vozes.

MÁRMORA, L. 1986. El concepto socialista de nación. México: Siglo XXI.

MARX, K. 1978. "Para a crítica da economia política". In: Manuscritos econômico-filosóficos e outros textos. São Paulo: Abril Cultural.

; ENGELS, F. 1967. Manifesto del Partito Comunista. Torino: Giulio Einaudi Editore.

. 1999. A ideologia alemã. São Paulo: Hucitec. 
MURPHY, C. N. 2005. Global institutions, marginalization, and development. Londres: Routledge.

NOGUEIRA, J. P.; MESSARI, N. 2005. Teoria de relações internacionais. Rio de Janeiro: Elsevier.

NYE JR., J. S. 2002. The paradox of american power: why the world's only superpower can't go it alone. Oxford: Oxford University Press.

OHMAE, K. 1996. O fim do Estado-nação: a ascensão das economias regionais. Rio de Janeiro: Campus.

RENOUVIN, P. 1966. Etudes d'histoire des relations internationals. Paris: PUF.

RICARDO, D. 2004. Works and correspondence of David Ricardo. Londres: Liberty Fund Inc.

ROSECRANCE, R. 1986. The rise of the trading stade. Nova York: Basic Books.

ROSENBERG, J. 1994. The empire of civil society: a critique of the realist theory of international relations. Londres: Verso.

RUPERT, M. 2007. "Alienação, capitalismo e o sistema interestados”. In: GILL, S. (org.). Gramsci, materialismo histórico e relações internacionais. Rio de Janeiro: Ed. UFRJ.

RUSSETT, B.; STARR, H. 1992. La politica mondiale. Bologna: Il Mulino.

SARFATI, G. 2005. Teorias de relações internacionais. São Paulo: Saraiva.

SKOCPOL, T. 1984. Vision and method in historical sociology. Cambridge: Cambridge University Press.

SMITH, A. 1999. A riqueza das nações. Lisboa: Calouste Gulbenkian.

STRANGE, S. 1988. State and markets: an introduction to international political economy. Londres: Pinter.

TESCHKE, B. 2003. The myth of 1648: class, geopolitics and the making of modern international relations. Londres: Verso.

; LACHER, H. 2007. "The changing 'logics' of capitalist competition”. Cambridge Review of International Affairs, vol. XX, n. 4, pp. 565-580.

VELASCO E CRUZ, S. C. 2007. Trajetórias: capitalismo neoliberal e reformas econômicas nos países da periferia. São Paulo: Ed. Unesp.

WALLERSTEIN, I. 1979. El moderno sistema mundial. México: Siglo XXI Editores.

WALTZ, K. N. 1979. Theory of international politics. Nova York: Random House. 2000. "Structural realism after the cold war". International Security, vol. 25, n. 1, pp. 5-41. 
WEBER, M. 1985. A ética protestante e o espírito do capitalismo. São Paulo: Livraria Pioneira.

WENDT, A. 1999. Social theory of international politics. Cambridge: Cambridge University Press.

\section{Outros materiais}

ROSENBERG, J. 2007. "Marxism and international relations”. Material didático desenvolvido para o curso de graduação em Relações Internacionais da Universidade de Sussex. Disponível em: <www. justinrosenberg.org>. Acesso em: 12/10/2010. 
Palavras-chave: Economia solidária; empresas; igualdade; renda; trabalho.

\section{THE RELATION BETWEEN EQUALITY AND VIABILITY IN THE SOLIDARITY ECONOMY ENTERPRISES}

The solidarity economy can be considered an alternative to generate income, face poverty and break the social logic of inequalities, since it promotes the protagonism of the poor, needed by political interventions in this field to achieve efficiency. The article discusses this subject by analyzing evidences brought up by qualitative researches and by the final data of the first Brazilian national mapping of solidarity economy. Comparing the general characteristics of Brazilian companies registered in the national statistics with the solidarity economy enterprises, certain singularities stand up, such as the tendency of the solidarity enterprises to protect jobs and hold equalitarian principles regarding income and benefits

264 arising from their economic activities. This regime of equality is a component of their specific social production structure.

Key-words: Solidarity economy; enterprises; equality; income; work.

\section{A CONTRIBUIÇÃO MARXISTA PARA O ESTUDO DAS RELAÇÕES INTERNACIONAIS}

TULLO VIGEVANI

ALINE REGINA ALVES MARTINS

MANOELA MIKLOS

PRISCILA RODRIGUES

$\mathrm{O}$ artigo analisa a contribuição marxista para o estudo das relações internacionais enfatizando a dimensão histórica nas formações sociais e a economia política como variável fundamental. Assim, o marxismo oferece instrumentos para 
uma análise abrangente das relações internacionais, desconstruindo o conceito de Estado tal qual entendido pelas teorias dominantes da área.

Palavras-chave: Relações internacionais; teoria das relações internacionais; marxismo; teoria crítica.

\section{THE MARXIST CONTRIBUITION TO THE STUDY OF INTERNACTIONAL RELATIONS}

The article examines the marxist contribution to the study of international relations stressing the historical dimension in the social groups and political economy as a fundamental variable. Thus, marxism provides resources to a comprehensive analysis of international relations, deconstructing the concept of state as is understood by the dominant theories in the area.

Keywords: International relations; international relations theory; marxism; critical theory.

\section{EFEITOS DIRETOS, INDIRETOS E TARDIOS: TRAJETÓRIAS DA TRANSIMISSÃO INTERGERACIONAL DA PARTICIPAÇÃO POLÍTICA}

MARIO FUKS

O artigo propõe um modelo para explicar o processo mediante o qual os jovens se tornam cidadãos participativos. Veremos que este ocorre de duas formas complementares. A primeira é a transmissão imediata, embora, em grande medida, estimulada por efeitos indiretos, das rotinas participativas. A segunda depende de um processo de longa duração, gerando a participação como efeito tardio. O estudo mostra que a participação política dos pais é a forma mais eficaz de se "ensinar" participação política aos filhos. Em relação às condições socioeconômicas da família, embora 